\title{
Germination of Allanblackia floribunda Seeds: The Effect of Soak Duration in Fluridone on Germination and Seedling Growth
}

\author{
Faith Ileleji, Elsie I. Hamadina*, Joseph A. Orluchukwu \\ Crop and Soil Science Department, Faculty of Agriculture, University of Port Harcourt, Port Harcourt, Nigeria
}

Email address:

elsieile@yahoo.com (E. I. Hamadina)

\section{To cite this article:}

Faith Ileleji, Elsie I. Hamadina, Joseph A. Orluchukwu. Germination of Allanblackia floribunda Seeds: The Effect of Soak Duration in Fluridone on Germination and Seedling Growth. Agriculture, Forestry and Fisheries. Vol. 4, No. 3, 2015, pp. $142-147$. doi: $10.11648 /$ j.aff. 20150403.20

\begin{abstract}
Allanblackia seeds contain about $72 \%$ white fat (mostly of oleic and stearic acid), with high medicinal and industrial value, but the plant has not been domesticated, so seeds are only gotten from the wild. The demand for seeds of the wild Allanblackia floribunda exceeds supply and efforts to domesticate the plant to increase seed availability have been unsuccessful due to long seed dormancy periods. Soaking scarified seeds from immature fruits in water or fluridone shortened dormancy to less than 3 months, but the effects of different soak durations on germination, dormancy and seedling vigor, are not fully understood. This study aimed to determine the effects of three soak durations $(1,6$, and $12 \mathrm{~h})$ in water or fluridone (10 $\mu \mathrm{M}$ or $30 \mu \mathrm{M}$ ) on seed germination and seedling growth. The study was a $3 \times 3$ factorial experiment arranged in a Completely Randomized Design, using scarified immature seeds. At 16 weeks after treatment, seedlings were transplanted into polypots filled with topsoil and assessed weekly for the effects of treatments on seedling growth (leaf number and plant height). The \% germination increased as the duration of soak in water or $10 \mu \mathrm{M}$ fluridone increased from 1 to $12 \mathrm{~h}$. The tendency to obtain 75 $100 \%$ germination was higher when seeds were soaked in $10 \mu \mathrm{M}$ fluridone (i.e., for 6 or $12 \mathrm{~h}$ ) as compared to soaking in water for up to $12 \mathrm{~h}$. The shortest duration (72 d, i.e., approx. 2.5 months) to achieve $>75 \%$ germination was when Allanblackia seeds were soaked for $6 \mathrm{~h}$ in $10 \mu \mathrm{M}$ fluridone. Soaking the seeds for $12 \mathrm{~h}$ in $10 \mu \mathrm{M}$ fluridone resulted in $100 \%$ germination in 3 months. At transplanting, seedlings from fluridone treated seeds were taller, and had more leaves than those from seeds soaked in water for 1 or $6 \mathrm{~h}$, but the reverse was observed in seedlings from seeds soaked for $12 \mathrm{~h}$ in water. However, these effects diminished after 2 weeks, when the seedlings have become established. This study has shown a promising method for achieving rapid and efficient germination of Allanblackia seeds with no noticeable adverse effects on seedling establishment.
\end{abstract}

Keywords: Allanblackia floribunda, Rapid Germination, Seed Dormancy, Fluridone

\section{Introduction}

Allanblackia trees produce large berry-like fruits that contain seeds (30 to 50) of high food, cosmetic and pharmaceutical importance (Foma and Abdala, 1985, Bonanome and Grundy, 1988). Allanblackia seeds are mainly obtained from collections of wild mature fruits that drop off the tree. The seeds contain about $72 \%$ white fat (Foma and Abdala, 1985) that remains solid at ambient temperatures and consists mostly of oleic and stearic acid (Eckey, 1954; Hilditch, 1958, $c f$ http://www.fao.org/docrep/X5043E0d.htm). Oleic and stearic acids are reported to lower plasma cholesterol levels (Bonanome and Grundy, 1988). Also, the fat from Allanblackia seeds has a relatively high melting point $\left(35^{\circ} \mathrm{C}\right)$, which makes it more valuable than other fats because it can be used without the need to transform its consistency for margarines and similar products (Nkengfack et al., 2002). These characteristics make Allanblackia seeds extremely valuable to food and cosmetic industries.

Currently, the demand for Allanblackia seeds is much higher than its supply: only $20 \%$ of the demand is obtainable from the wild (Leakey et al., 2000; Adubofuor et. al., 2013). To produce large number of Allanblackia trees, the seeds must be domesticated (Munjuga et al., 2008). Unfortunately, efforts to domesticate Allanblackia through seed propagation is hindered by the lack of a method to induce spontaneous 
and high rate of seed germination (Atangana et al., 2006; Ofori et al., 2011). Allanblackia seeds could remain dormant for as long as 2 years, and only one in ten seeds eventually germinates (Ofori et al., 2011).

The need to increase the rate of Allanblackia seed germination, and possible methods to stimulate early germination, is the drive behind research aimed to understand the contol of Allanblackia seed dormancy. In a previous study, the duration of dormancy, from treatment of seeds obtained from mature fruits to germination, was reduced to 4-10 months, and germination was increased to $40 \%$ by: (1) buring the fruits in sand for 2-3 months to soften the seed coat followed by scarification and storage in black polybags, or (2) scarifing the seeds followed by storage in black polybags (Peprah et al., 2008). Seed rot is however high under these methods. A novel method of germinating Allanblackia using scarified seeds from immature fruits was recently proposed (Ileleji and Hamadina, 2015), which led to $75 \%$ germination in 72 days (2.5 months) by soaking scarified seeds from immature fruits for $6 \mathrm{~h}$ in $10 \mu \mathrm{M}$ fluridone or water, as compared to $50 \%$ (in $100 \mathrm{~d}$ ) for seeds from mature fruits. The response of the seeds soaked in fluridone and water suggests that young scarified seeds still exhibit dormancy. We propose that this may be caused by the presence of growth inhibitor(s), perhaps abscisic acid, and that the effect of the inhibitor is related to the duration of soak in water or ABA inhibitor. Fluridone is a plant growth regulator that is known to induce germination in many plant parts that exhibit dormancy by competitively inhibiting $\mathrm{C}_{40}$ carotenoid, which is the precursor of abscisic acid (ABA) biosynthesis (Fong et al., 1983; Zeevaart and Creelman, 1988). Also, ABA can leach out of plant tissues soaked in water (Villiers and Wareing, 1960; loveys and Van Dijk, 1988). However, the most effective soak duration in fluridone or water on germination of scarified seeds from immature fruits is not known. Also, information on the effects of such approach on seedling establishment and growth is hard to come by. The main aim of this study is to determine the effect of soak duration $(1,6$, and $12 \mathrm{~h})$ in water or fluridone $(10$ or $30 \mu \mathrm{M})$ on seed germination and seedling growth of Allanblackia.

\section{Materials and Methods}

\subsection{Collection of Immature Allanblackia Fruits}

Allanblackia floribunda fruits were collected in the month of August from Rivers State Sustainable Development (RSSDA) Allanblackia Project site at Igbu Idonka, Etche, Rivers State of Nigeria. In this study, all the fruits were plucked by detaching from the tree either at the point of attachment of the fruit stalk (pedicel) to the stem or along the stalk. Allanblackia floribunda was choosen because it is the dorminant Allanblackia species found in Nigeria.

\subsection{Fruit and Seed Assessment for Maturity}

The plucked fruits were assessed for maturity using the indices detailed by Bewley and Black (1994), even when the plucked fruits were expected to be immature. The rationale for collecting immature fruits in this study relates to the hypothesis that dormancy may be avoided by collecting seeds before the desiccation and hardening of the seed coat, and that recalcitrant seeds, when collected before the hardening of the seed coat are germinable and may require no pretreatment to germinate (Bewley and Black, 1994).

\subsection{Chemicals Used}

The chemicals and reagents used in this study were fluridone (1-methyl-3-phenyl-5-[3-trifluoromethy1= (phenyl)] -4-(1H)-pyridinone), Dimethyl sulphuroxide (DMSO), nitric acid, potassium hydroxide and sodium hypochlorite. $1 \mathrm{~N}$ $\mathrm{KOH}$ (potassium hydroxide) was used as base stabilizer and $\mathrm{HNO}_{3}$ (Nitric acid) as acid stabilizer, and sodium hypochlorate as disinfectant. Fluridone was purchased from Chem Services Inc., West Chester, USA. Fluridone was chosen because it is known to inhibit ABA biosynthesis and induce germination. Also, if dormancy in immature Allanblackia seeds resulted from ABA concentration then, inhibiting ABA biosynthesis should induce early germination.

\subsection{Fruit and Seed Preparation}

Allanblackia floribunda fruits were wrapped in plantain leaves for two weeks to soften them prior to seed extraction. The seeds were extracted from the fruits, cleaned, weighed, scarified and weighed again. Scarification was done because seeds tend to germinate faster when the hard seed coat is removed or thinned down.

\subsection{Experimental Treatments}

Scarified seeds from immature fruits were soaked in one of three fluridone (FLU) concentrations $(0 \mu \mathrm{M}, 10 \mu \mathrm{M}$, and 30 $\mu \mathrm{M}$ fluridone solutions) for one, six or twelve hours. Treated seeds were then stored/incubated in disinfected transparent plastic containers wrapped in black polyethylene bags. The seeds were observed weekly for germination. Thus, there were nine treatment combinations: $0 \mu \mathrm{M}$ FLU $1 \mathrm{~h}$ soak duration (control), $0 \mu \mathrm{M}$ FLU $6 \mathrm{~h}$ soak duration, $0 \mu \mathrm{M}$ FLU $12 \mathrm{~h}$ soak duration, $10 \mu \mathrm{M}$ FLU $1 \mathrm{~h}$ soak duration, $10 \mu \mathrm{M}$ FLU 6h soak duration, $10 \mu \mathrm{M}$ FLU $12 \mathrm{~h}$ soak duration and 30 $\mu \mathrm{M}$ FLU $1 \mathrm{~h}$ soak duration, $30 \mu \mathrm{M}$ FLU 6h soak duration, 30 $\mu \mathrm{M}$ FLU $12 \mathrm{~h}$ soak duration. A one-hour soak duration was considered the maximum duration it could take to wash and surface-sterilizes seeds in a routine seed preparation activity.

\subsection{Seed Incubation and Incubation Conditions}

Scarified, treated seeds were placed in sterile transparent plastic containers. The containers were kept moist by spraying some distilled water on the inner part of the cover. Each container was then wrapped in a black polythene bag and placed in a warm screen house.

The sides of the screen house were covered with white polyethylene film to about $3 / 4$ of the height of the screen house while the $1 / 4$ of the screen house was covered with white net for ventilation. Temperature and relative humidity, 
inside the seed storage containers, and screen house were monitored using a $433 \mathrm{MHZ}$ cable free Oregon scientific sensor model BTHR968.

\subsection{Data Collection}

Seeds were observed weekly for shoot bud emergence until 16 WAT. To study the effect of treatments on seedling growth, all germinated seeds were transplanted at 16 weeks after treatment when seedling height was $\geq 1.8 \mathrm{~cm}$. One seedling was transplanted into a polypot filled with $3 \mathrm{~kg}$ top soil. The height of each plant was measured weekly for eight weeks. The number of leaves per plant was counted weekly.

\subsection{Experimental Design and Data Analysis}

This experiment was a $3 \times 3$ factorial experiment arranged as a Completely Randomized Design; with three fluridone concentrations and three soak durations. Data was analyses using GenStat Release 10.3DE, Copyright 2011, VSN International Ltd. Rate of germination was determined using percentages. Data on duration from treatment date to germination was analyzed using survival data analysis. Survival data analysis is a statistical tool for analyzing data where the outcome variable is time until the occurrence of an event, which in this study was shoot emergence. This program is most suitable in the analysis of data on duration from a defined time to the occurrences of a named event, and where some elements in the study survive (i.e., where some seeds do not germinate) longer than the period of the study (Collet, 1994; Hoon, 2008). Thus for such seeds, the duration to germination is unknown but at least as long as the duration of the study and so, it is censored and used in the model. Censoring is important in survival analysis, representing a particular type of missing data. Also, because the distribution of this type of data is usually not a normal distribution, the regular Analysis of Variance (ANOVA) cannot be used in this analysis.

Plant height data was analyzed using two-way analysis of variance. Means were separated using standard error of difference (SED). Leaf number data was square root transformed and then analyzed using General Treatment Structure (no blocking) in analysis of variance (ANOVA).

\section{Results}

\subsection{Fruit and Seed Assessment for Maturity}

Fruit assessment at collection suggests that the fruits were immature; the fruit was greenish with no split or opening on the fruit's surface, the pedicels/stalk was still attached to the fruits, the fruit-pulp was hydrated, hard and difficult to cut through and the seeds were tightly held to the pulp. The seeds on the other hand were germinable; they appeared well filled, embryo was present, they sunk in floating tests for germinability, the endosperm was slightly hard and the seed coat was easy to cut through. Average seed fresh and dry weights were $6.5 \mathrm{~g}$ and $0.18 \mathrm{~g}$ respectively and percentage moisture content was up to $94 \%$.

\subsection{Percentage Shoot Emergence}

Shoot emergence (germination) was first noticed at 6 WAT. By 7 WAT, shoot emergence was observed in many treatments and shoots were up to $2 \mathrm{~mm}$. Soaking seeds for 1 $\mathrm{h}$ in water (Control) led to $60 \%$ shoot emergence by 11 WAT and $>70 \%$ by 14 WAT (Figure 1 ). Also, soaking the seeds in water for 6 hours led to $60 \%$ by 8 WAT and above $70 \%$ by 14 WAT. For the $12 \mathrm{~h}$ soak in water treatment, percentage shoot emergence was nearly $100 \%$ by the 14 WAT. In the fluridone treatments, soaking seeds in $10 \mu \mathrm{M}$ FLU for $1 \mathrm{~h}$, led to more than $45 \%$ shoot emergence by 14 WAT. Increasing the soak duration in $10 \mu \mathrm{M}$ FLU to $6 \mathrm{~h}$ increased the percentage germination $(80 \%$ by 10 WAT). Soaking the seeds for $12 \mathrm{~h}$ in $10 \mu \mathrm{M}$ FLU led to almost $100 \%$ germination in 14 WAT. Seeds soaked in fluridone concentration of 30 FLU $1 \mathrm{hrs}, 30$ FLU 6hrs, and 30 FLU $12 \mathrm{~h}$ lead to less than $40 \%$ by 9 WAT, 14 WAT and 11 WAT respectively (Figure 1).

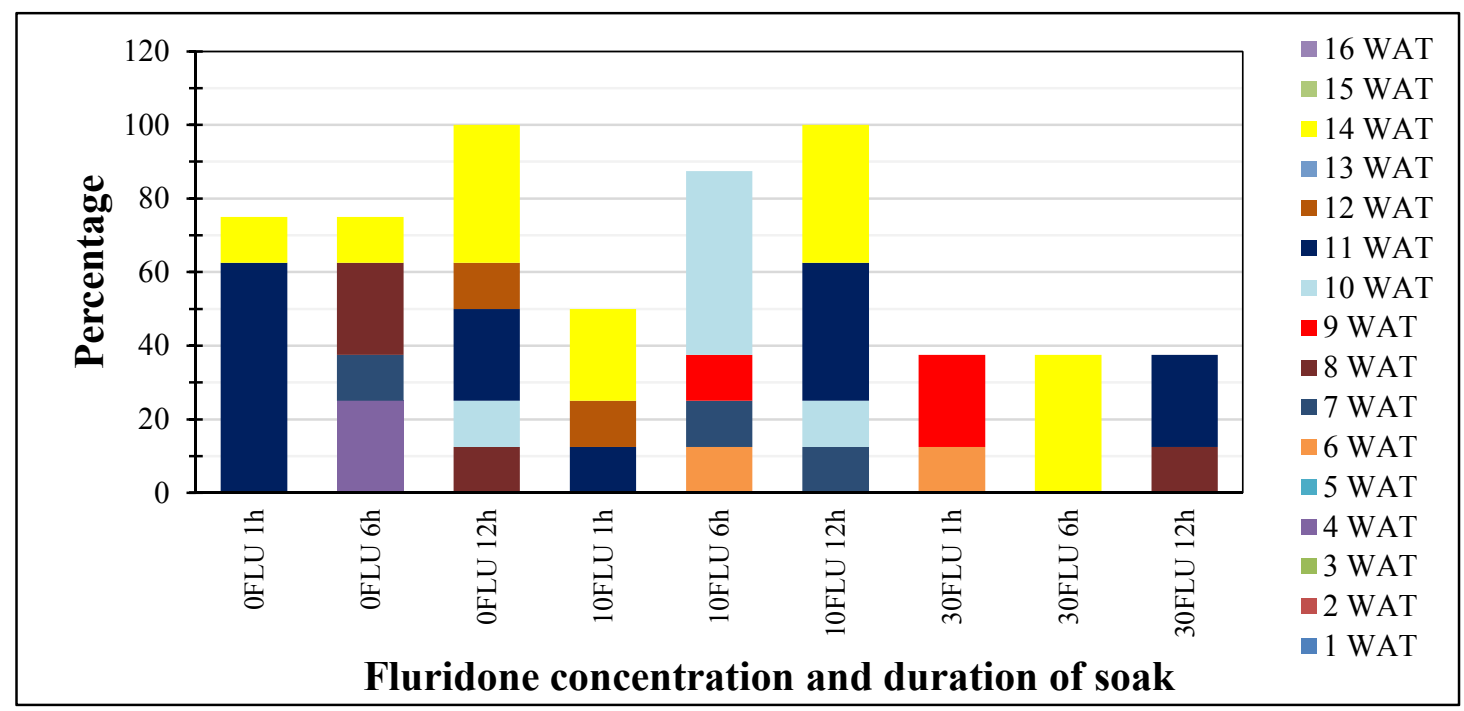

Figure 1. Effect of fluridone concentration and soak duration on rate and percentage shoot emergence 
Thus, prolonging the soak duration in water to $12 \mathrm{~h}$ increased the percentage seed germination. Similarly, percentage seed germination increased with increase in soak duration in $10 \mu \mathrm{M}$ fluridone. However, percentage shoot emergence was inhibited by soaking seeds in $30 \mu \mathrm{M}$ fluridone compared to the control or $10 \mu \mathrm{M}$ fluridone treatment, and prolonging the duration of soak in $30 \mu \mathrm{M}$ fluridone for $12 \mathrm{~h}$ did not significant change rate or percentage seed germination.

\subsection{Effects of Treatments on Time Taken to Germinate}

The Kaplan Meier log cumulative hazard (germination) curve shows that the treatment curves were significantly different at $\mathrm{P}<0.01$ (Figure 2). A maximum of $50 \%$ germination occurred in 79 days when scarified Allanblackia seeds collected from immature fruits were soaked for $1 \mathrm{~h}$ in water, i.e., $0 \mu \mathrm{M}$ FLU $1 \mathrm{~h}$ (control). In contrast, the duration to $50 \%$ germination was significantly hastened by $20 \mathrm{~d}$ by soaking seeds for $6 \mathrm{~h}$ in water. However the treatment did not lead to $70 \%$ or greater germination by the end of the study. Increasing the duration of soak in water to $12 \mathrm{~h}$ led to greater than 50 and $75 \%$ germination in 100 days.

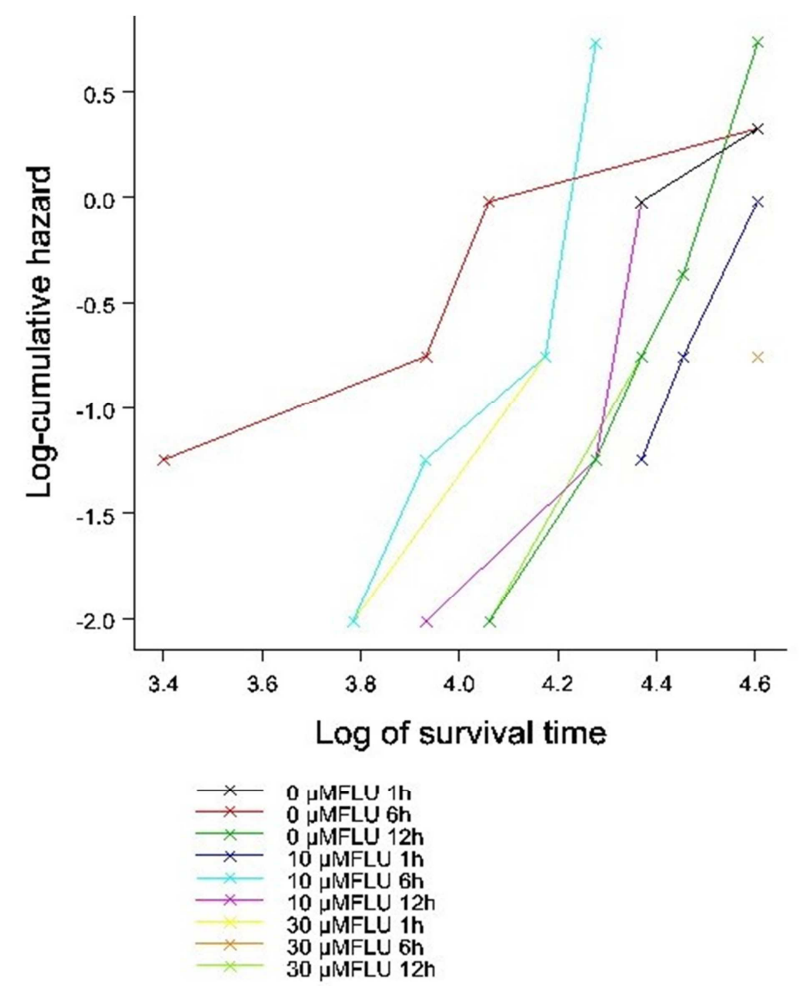

Figure 2. Kaplan-Meier log cumulative hazard (germination) curve for the effect of treatment on time taken to germinate for Allanblackia seeds. Log rank test of equality; $P<0.01$; test statistic $=21.264$.

In the $10 \mu \mathrm{M}$ fluridone treatments, $50 \%$ germination was observed in 72 and $79 \mathrm{~d}$ when seeds were soaked in $10 \mu \mathrm{M}$ FLU for 6 or $12 \mathrm{~h}$ respectively. Greater than $75 \%$ germination was obtained in 72-100 d when seeds were soaked in $10 \mu \mathrm{M}$ FLU for 6 or $12 \mathrm{~h}$ respectively. These treatments clearly stimulated germination in more seeds and shortened the duration to germination compared to the control. However, the effects of these treatments were comparable to that of a prolonged (12 h) soak in water.

In the $30 \mu \mathrm{M}$ fluridone treatments, neither 50 nor $75 \%$ germination was obtained by the end of the study. Prolonging the soak duration did not hasten the duration to germination. Only $25 \%$ germination was possible with these treatments.

\subsection{Effect of Treatments on Seedling Growth}

\subsubsection{Effect on Number of Leaves Per Seedling}

At transplanting and throughout the study period, the number of leaves per plant did not differ significantly $(\mathrm{P}<0.05)$ across the treatments. The mean number of leaves (square root transformed) was 1.101, 1.330, 0.208, 0.202, and 0.230 at $0,2,4,6$ and 8 weeks after transplanting.

\subsubsection{Effect on Seedling Height}

At transplanting, seedlings were taller under most of the fluridone treatments than in the control except where the seedlings developed from seeds that were soaked for $12 \mathrm{~h}$ in either 10 or $30 \mu \mathrm{M}$ FLU (Table 1). The tallest seedlings were observed under the $30 \mu \mathrm{M}$ FLU $6 \mathrm{~h}$ treatment. At 2, 4, 6 and 8 weeks after transplanting, there were no significant $(\mathrm{P}<0.05)$ differences in seedling height across treatments.

Table 1. Seedling plant height at transplant as affected by treatments.

\begin{tabular}{llll}
\hline \multicolumn{4}{l}{ Duration of Soak (h) } \\
\hline Fluridone $(\boldsymbol{\mu M})$ & $\mathbf{1}$ & $\mathbf{6}$ & $\mathbf{1 2}$ \\
\hline 0 & 1.90 & 2.83 & 3.30 \\
10 & 3.27 & 2.67 & 2.00 \\
30 & 2.43 & 3.90 & 2.23 \\
S.E.D & 0.638 & & \\
\hline
\end{tabular}

\section{Discussion}

This study seeks to determine the effect of soak duration (1, 6 , and $12 \mathrm{~h})$ in water or fluridone $(10 \mu \mathrm{M}$ and $30 \mu \mathrm{M})$ on germination of scarified Allanblackia seeds collected from immature fruits, and on subsequent seedling growth. In this study, percentage germination increased as the duration of soak in water or $10 \mu \mathrm{M}$ fluridone increased from 1 to $12 \mathrm{~h}$. This effect suggests the presence of an endogenous growth inhibitor, possibly abscisic acid, that is soluble in water and whose activity is inhibited by fluridone (an inhibitor of Abscisic acid biosynthesis). Abscisic acid (ABA) is long known to leach in water allowing dormant seeds to germinate (Villiers and Wareing, 1960). Also, fluridone has severally been shown to inhibit ABA biosynthesis/ content in seeds and tubers (Zeevaart and Creelman, 1988; Le Page-Degivry et al., 1990; Mulwa and Nwanza, 2006). Although information on the changes in ABA content of Allanblackia seeds during seed development and through germination is rare, many studies have shown that its content reduces as dormant seeds/ tubers progress towards germination (Zeevaart and Creelman 1988; Suttle, 1995). We suggest therefore that prolonged soak in water may be necessary to significantly leach out $\mathrm{ABA}$ while prolonged soak in fluridone may be necessary to 
prevent the wearing off of a fluridone effect over the long period before germination. Wearing off effect of fluridone has been reported in prolong invitro (Hamadina et al., 2010) and open field pot studies (Hamadina and Eze, 2013) on yam dormancy. In the $30 \mu \mathrm{M}$ fluridone treatments, however, increasing the duration of soak did not increase percentage germination nor did it induce early seed germination. The tendency of $30 \mu \mathrm{M}$ fluridone to slow down the Allanblackia seed germination has been reported (Ileleji and Hamadina, 2015).

The likelihood of obtaining $75-100 \%$ germination is higher when germinable, scarified, seeds from immature Allanblackia fruits are soaked in $10 \mu \mathrm{M}$ fluridone (i.e., for 6 or $12 \mathrm{~h}$ ) than in water (i.e., for $12 \mathrm{~h}$ ). Soaking Allanblackia seeds for $6 \mathrm{~h}$ in $10 \mu \mathrm{M}$ fluridone is recognized for its role in bringing about over $75 \%$ (indeed $80 \%$ ) germination over the shortest period of time (72 d, i.e., approx.. 2.5 months). Soaking seeds for $12 \mathrm{~h} 10 \mu \mathrm{M}$ fluridone or in water is recognized for bring about maximum percentage (100\%) germination though over a long period of $100 \mathrm{~d}$, i.e., approx. 3.5 months). Although the use of water for germinating seeds is cheaper and safer, this results shows that the use of a recognized inhibitor of $\mathrm{ABA}$ biosynthesis is a more effective method of stimulating germination than the use of a method that leaches out already biosynthesized growth inhibitor. Further studies are however required to confirm this.

The effect of fluridone treatments on the seedling growth parameters reported in this study suggests that fluridone, particularly at $10 \mu \mathrm{M}$, supports shoot growth rather than inhibit it but this effect may be transient; declining as the seedlings becomes more autotrophic. Although fluridone have been shown to cause reduction in rice mesocotyle growth (Watanabe et al., 2001), it has also been shown to increase micro tuber number and support shoot growth in yam (Hamadina et al., 2010) and increase germination and seedlings growth of Mungbean (Thind et al., 1997). The transient tendency of fluridone observed in this study may prove useful in Allanblackia germination effort but this need to be verified. Thus, this study confirms that Allanblankia seeds from immature fruits harvested in the month of August have very high germination rates $(70-100 \%)$ that are dependent on soak duration in water or fluridone. The outcome of this study has high consequence for large scale seedling propagation when compared to a germination rate of $<10 \%$ obtainable over 6 to 24 months when seeds from mature fruits are propagated or the $6-40 \%$ germination obtainable over 10 months when seeds from mature fruits are scarified and incubated in black polythen bags.

\section{Conclusion}

In conclusion, this study has shown a promising method for achieving rapid and efficient germination of Allanblackia seeds with no noticeable adverse effects on seedling establishment. The outcome of this study has high potential for large scale seedling propagation using seeds from mature fruits are scarified and incubated in black polythen bags.

\section{Acknowledgement}

The authors wish to acknowledge assistance of the Rivers State Sustainable Development Agency (RSSDA) for providing the fruits used in this study.

\section{References}

[1] Adubofuor, J., W. Sefah and J. H. Oldham. 2013. Nutrient composition of Allanblackia paviflora seed kernels and oil compared with some plant fats and oils and application of the oil in soap preparation. J. Cereals and Oil seeds, 4(1): 1-9.

[2] Atangana, A. R., Z. Tchoundjeu, E.K. Asaah, A.J. Simons, and D.P. Khasa. 2006. Domestication of Allanblackia floribunda: Amenability to vegetative propagation. Forest Ecology and Management 237: 246-251. doi: 10.1016/j.foreco.2006.09.081.

[3] Bewly J. D., and Black, M. 1994. Seeds - Physiology of development and germination. Plenum Press, New York, 445 pp.

[4] Bonanome, A., and S.M. Grundy. 1988. Effect of dietary stearic acid on plasma cholesterol and lipoprotein levels. New England Journal of Medicine 318(19): 1244-1248.

[5] Collet, D. (1994). Modelling Survival Data in Medical Research. Chapman and Hall, London.

[6] Eckey, E.W., Vegetable Fats and Oils, Reinhold Publishing Corp., 1954. pp 695-6

[7] Foma, M., and T. Abdala. 1985. Kernel oils of seven species of Zaire. Journal of the American Oil Chemists Society 62(5): 910-911.

[8] Fong F, Koehler DE, Smith JD. 1983. Fluridone induction of vivipary during maize seed development. In: Kruger JE, LaBerg DE, eds. Third International Symposium on PreHarvest Sprouting in Cereals. Boulder, Co. USA: Westview Press, 188-95.

[9] Hamadina, E.I., and G. Eze. 2013. Pre Tuber Application of Fluridone: Effect on Vegetative Growth and Seed Tuber Dormancy in Yam (D. alata). American Journal of Experimental Agriculture, Vol. 4(4): 415-426, 2014

[10] Hamadina, E.I.; Craufurd, P.Q.; Battey, N.H.; Asiedu, R. 2010. In vitro micro-tuber initiation and dormancy in yam. Annals of Applied Biology vol. 157 issue 2 September 2010. p. 203-212

[11] Hilditch, Chemical Contribution of Natural Fats. pp 264-5 TANG. Tr. Bull., 1958, Part I, p.13

[12] Hoon, T.S. (2008). Using Kaplan Meier and Cox regression in survival analysis: An example. ESTEEM, Vol.4, pp.3-14.

[13] Ileleji, F. O. and E. I., Hamadina. 2015. Improving Seed Germination in Allanblackia floribunda: Effect of Seed Age and Fluridone. Nigerian Journal of Agriculture, Food and Environment, Vol. 11(2):24-32

[14] Le Page-Degivry M-T, Barthe P, Garello G. 1990. Involvement of endogenous abscisic acid in onset and release of Helianthus annuus embryo dormancy. Plant Physiology 92, 1164-8.

[15] Leakey, R.R.B., J-M.Fondoun, A. Atangana, and Z. Tchoundjeu. 2000. Quantitative descriptors of variation in the fruits and seeds of Irvingia gabonensis. Agroforestry Systems 50: $47-58$. 
[16] Loveys, B. R. and van Dijk, HM. 1988. Improved extraction of abscisic acid from plant tissues. Austr. J, Plant Physiol. $15: 421-427$

[17] Mulwa R.M.S., Nwanza L.M. (2006) Biotechnology approaches to developing herbicide tolerance/selectivity in crops. African journal of Biotechnology,5,396-404

[18] Munjuga, M., Ofori, D., Sawe, C., Asaah, E., Anegbeh, P., Peprah, T., Mpanda, M., Mwaura L., Mtui, E., Sirito, C., Atangana, A., Henneh, S., Tchoundjeu, Z., Jamnadass, R., Simons, A.J. (2008). Allanblackia propagation protocol. World Agroforestry Centre (ICRAF), Nairobi, Kenya, ISBN 978-929059-231-0.

[19] Nkengfack, A.E., G.A. Azebaze, J.C. Vardamides, Z.T. Fomum, and F.R. van Heerden. 2002. A prenylatedxanthone from Allanblackia floribunda. Phytochemistry60: 381-384.

[20] Ofori, D.O., Peprah, A.T., Cobbinah, J.R., Atchwerebour, H.A., Osabutey, F., Tchoundjeu, Z., Simons, A.J., Jamnadass, R. 2011. Germination requirements of Allanblackia parviflora seeds and early growth of seedlings. New Forest, 41:337-348 DOI: $10.1007 / \mathrm{s} 11056-011-9252-1$.

[21] Ofori, D.O., Peprah, A.T., Cobbinah, J.R., Atchwerebour, H.A., Osabutey, F., Tchoundjeu, Z., Simons, A.J., Jamnadass, R. (2011). Germination requirements of Allanblackia parviflora seeds and early growth of seedlings. New Forest, 41:337-348 DOI: $10.1007 / \mathrm{s} 11056-011-9252-1$.

[22] Peprah T, Moses Munjuga, Daniel Ofori, Corodius Sawe, Ebenezar Asaah,Paul Anegbeh, Mathew Mpanda, Lucy Mwaura, Eustack Mtui, Chrispine Sirito, Alain Atangana, Samuel Henneh Zac Tchoundjeu, Ramni Jamnadass and Tony Simons 2008. Allanblackia propagation protocol.

[23] Suttle, J. C. (1995). Postharvest changes in ABA levels and ABA metabolism in relation to dormancy in potato tubers. Physiologia Plantarum, 95, 233-240.

[24] Thind, S. K., Chanpreet and Miridula. 1997. Effect of fluridone on free sugar level in heat stressed mungbean seedlings. Plant Growth Regulation 22(1):19-22

[25] Villiers, T.A. and Wareing, P.F. 1960. Interaction of growth inhibitor and natural germination stimulator in the dormancy of Fraxinus excelsior L. I, 185, 112-114.

[26] Watanabe, H., Takahashi, K., and Saigusa, M. 2001. Morphological and anatomical effects of abscisic acid (ABA) and fluridone (FLU) on the growth of rice mesocotyls. Plant Growth Regulation 34(3):273-275

[27] Zeevaart, J.A.D., and Creelman, R.A. (1988).Metabolism and physiology of abscisic acid.Annu. Rev. Plant Physiol. Plant Mol. Biol. 39, 439-473. 